\title{
Research on semantic similarity between cloud manufacturing resource and demand service ontology
}

\author{
ZHANG Wei* ; WANG Ping; WANG Nianxin
}

School of Economics and Management, Jiangsu university of science and technology, Zhenjiang, P.R. China *18852890070@163.com

This is an open access article distributed under the Creative Commons Attribution License, which permits unrestricted use, distribution, and reproduction in any medium, provided the original work is properly cited.

\section{ARTICLE DETAILS}

\section{Article History:}

Received 02 october 2017 Accepted 06 october 2017 Available online 11 october 2017

\section{Keywords:}

cloud computing;mancufacturing resource;command service; similarity.

\section{ABSTRACT}

Aimed to match manufacturing resource and demand service more effectively under the cloud computing environment, this paper proposed a method for calculating similarity of cloud manufacturing resource and demand service ontology. Many research examined similarity of manufacturing resource ontology, but few of study paid attention to similarity between manufacturing resource and demand service. Moreover, existed study only described the difference of manufacturing resource from the aspect of syntax and semantics, without considering service attributes of manufacturing resource. Based on these, we explored similarity between cloud manufacturing resource and demand service from the perspective of service attributes of manufacturing resource to improve the efficiency of resource and demand service matching. Empirical study has confirmed that this method are valid to calculate the total similarity of cloud manufacturing resource and demand service ontology, which constructs the basis of research on manufacturing resource and demand service matching.

\section{Introduction}

With the rapid development of science technology, manufactory industry has merged with some emerging Information technology, such as cloud computing and Internet of Things, which generates a new service-oriented manufacturing mode, namely cloud manufactory ${ }^{[1-2]}$. Because of these merged technology, manufacturing firms has combined into a globalized resource demand service system and it enhance information communication and resource cooperation. However, enterprises describe the resource that they need in their own way and their resource demand descriptions depend on what manufacturing resource that they need. As a result, description of resource demand between manufhacturing firms can be very different with each other. Thus, it is necessary to calculate the similarity between manufacturing resource and demand service in order to help manufacturing resource demander to match their own need with manufacturing resource ${ }^{[3]}$.

Many research examined the calculation of ontology similarity and it can be divided into two aspects, which are syntax similarity and semantic similarity. Liao ${ }^{[4]}$ proposed a short text algorithm based on syntax by analyzing the characteristics of Chinese short text. Rada[ ${ }^{[5]}$ calculated semantic similarity according to shorter path. They proposed a metric, called Distance, which is the average minimum path length over all pairwise combinations of nodes between subsets. Tversky ${ }^{[6]}$ algorithm is one classic semantic similarity calculation method, but it ignores the location information of concepts in tree hierarchies.

And then, some scholars apply the method of similarity calculation into manufacturing resource field. Liu[7] proposed a new similarity calculation model for manufacturing resource ontology based on analysis on similarity calculation method and characteristics and role of manufacturing resources ontology. Ding ${ }^{[8]}$ puts forward a new method to calculating concept semantic similarity.

Although a few studies investigated manufacturing resource similarity computation, there are still many spaces that are worth pursing further. First, few studies paid attention to similarity between manufacturing resource and demand service. Second, these researches ignored requirement of attributes feature of manufacturing resource to service response. Based on these, this paper confirm that the similarity between manufacturing resource and demand service can be calculated validly, which provided research basis of matching manufacturing resource with demand service.

\section{Similarity calculation method}

(1)Similarity of information content

Definition 1.1: similarity of information content

$$
\left({ }_{1}, 2\right)=\frac{2()}{\left({ }_{1}\right)+\left({ }_{2}\right)}
$$

" $a$ " is the largest sharing of information of " $a_{1}$ "and " $a_{2}$ "in conceptual hierarchical relationships

(2) Name similarity

Definition 1.2: name similarity:

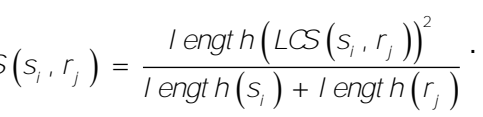

Among them, $\operatorname{NICS}\left(s_{i}, r_{j}\right)$ represents the name similarity of the manufacturing resource and the requirements service,length $\left(s_{j}\right)$ indicates the length of the name of the manufacturing resource, length $\left(s_{i}\right)$ represents the length of the name string for the requirements service, length $\left(\operatorname{LCS}\left(s_{i}, r_{j}\right)\right)$ represents the length of the public string between the manufacturing resources and the requirements services

\section{(3) Attribute semantic similarity}

The definition of similarity of attribute semantics for manufacturing resources and requirements services is shown in 1.3:

$$
\begin{gathered}
(,)=\frac{|\cap|}{|\cap|+\partial(,) /+(1-\partial(,)) /} \\
0 \leq \partial \leq 1 .
\end{gathered}
$$

" $a$ "represents the manufacturing resources, " $b$ "represents the demand 
service, and " $A$ " and " $B$ "are a set of descriptions of " $a$ " and " $b$ ". $|A \cap B|$ represents " $a$ " and " $b$ "the number of the same attributes. $A / B$ represents" $B$ " doesn't include parts of " $A$ ", $B / A$ "represents" $A$ "doesn't include parts of" $B$ ".

\section{(4)Comprehensive semantic similarity}

The strategy of this paper is first to preliminary screening of manufacturing resources and command services, On this basis, the similarity degree and semantic similarity are calculated,the distribution of weights is determined by contribution of comprehensive similarity of the Name similarity and attribute semantic similarity in particular value can be adjusted by the specific semantic environment specifically.

\section{Ontology construction}

In this paper, we study the classification structure of the mechanical processing of "umade" website, and select machining to construct object for ontology.According to the classification rules of machine_manufacturing of "umade" website, the ontology of figure 1 is established.

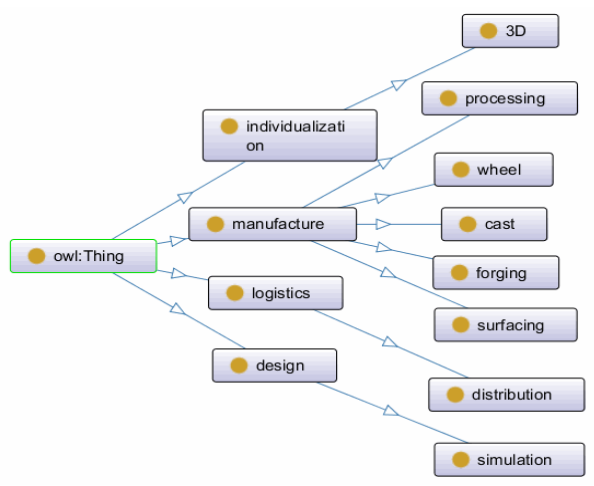

Figure 1 ontology construction diagram

In order to match manufacturing resources with command services, you need to do a similar calculation for manufacturing resources and command services, the ontology built in the structure of "umade"Which is rich in mechanical processing information, therefore this article uses the "umade" web page as a collection of manufacturing resources..This article uses web - scraper crawler software to extract manufacturing resources.The results of the extracted manufacturing resources are shown in table 1.

\section{Table 1 information extraction}

\begin{tabular}{c|c}
\hline Data attributes & Value \\
\hline Number of manufacturing resources & 885 \\
Number of web page & 89 \\
Type of Service & 9 \\
\hline
\end{tabular}

Table 1.1 shows that 885 manufacturing resources were extracted from the "umade" url, 89 web pages, and 9 types of requirements services.The description of the extracted manufacturing resources is shown in table 2.

Table 2 requirements service description information

\begin{tabular}{cc}
\hline machine_manufacturing \\
\hline Name & String \\
Description & String \\
Location & String \\
State & String \\
Number & Integer \\
Price & String \\
\hline
\end{tabular}

4. The similarity calculation of manufacturing resources and services

In this paper, WordNet [13] is selected as a reference. In WordNet, the total number of nouns is 88312 , and the nine ontology-related frequencies and definitions of the concept are explained as follows:

(1) cast; (2) processing; (12) wheel; (1) surfacing; (1) manufacture; (4) distribution; (1) 3D; (2) simulation; (1) individualization; (13) design; (1) logistics; (1) forging.
According to the formula of 1.1, the concept similarity of 9 kinds of demand services and manufacturing resources is calculated.This is shown in table 3 .

Table 3 concept similarity

\begin{tabular}{|c|c|c|c|c|c|c|c|c|}
\hline & $\begin{array}{l}3 \\
\mathrm{D} \\
\end{array}$ & $\begin{array}{l}\text { proce } \\
\text { ssing }\end{array}$ & $\begin{array}{l}\text { wh } \\
\text { eel }\end{array}$ & $\begin{array}{l}\mathrm{Ca} \\
\mathrm{st}\end{array}$ & $\begin{array}{c}\text { surfa } \\
\text { cing }\end{array}$ & $\begin{array}{c}\text { forg } \\
\text { ing }\end{array}$ & $\begin{array}{c}\text { distrib } \\
\text { ution }\end{array}$ & $\begin{array}{l}\text { simul } \\
\text { ation }\end{array}$ \\
\hline $3 \mathrm{D}$ & 1 & 0 & 0 & 0 & 0 & 0 & 0 & 0 \\
\hline $\begin{array}{c}\text { proces } \\
\text { sing }\end{array}$ & 0 & 1 & $\begin{array}{l}0.1 \\
43\end{array}$ & $\begin{array}{c}0 . \\
67\end{array}$ & 0.67 & $\begin{array}{c}0 . \\
67\end{array}$ & 0 & 0 \\
\hline wheel & 0 & 0.143 & 1 & $\begin{array}{l}0.1 \\
54\end{array}$ & $\begin{array}{c}0.15 \\
4\end{array}$ & $\begin{array}{l}0.1 \\
54\end{array}$ & 0 & 0 \\
\hline Cast & 0 & 0.67 & $\begin{array}{l}0.1 \\
54\end{array}$ & 1 & 1 & 1 & 0 & 0 \\
\hline $\begin{array}{c}\text { surfaci } \\
\text { ng }\end{array}$ & 0 & 0.67 & $\begin{array}{l}0.1 \\
54\end{array}$ & 1 & 1 & 1 & 0 & 0 \\
\hline $\begin{array}{l}\text { forgin } \\
\text { g }\end{array}$ & 0 & 0.67 & $\begin{array}{l}0.1 \\
54\end{array}$ & 1 & 1 & 1 & 0 & 0 \\
\hline $\begin{array}{c}\text { distrib } \\
\text { ution }\end{array}$ & 0 & 0 & 0 & 0 & 0 & 0 & 1 & 0 \\
\hline $\begin{array}{c}\text { simula } \\
\text { tion }\end{array}$ & 0 & 0 & 0 & 0 & 0 & 0 & 0 & 1 \\
\hline
\end{tabular}

As shown in table3 the similarity between "cast",

"surfacing"and "forging" is very high. the meaning of the filter of Manufacturing resources and services is that if a demand service and a manufacturing resource similarity is higher, then the next thing to consider is other manufacturing resources that are similar to manufacturing resources and don't have to consider the manufacturing resource similarity is low or manufacturing resources with a similarity of 0 .

When comparing its strings, you need to normalize the string.In this paper, extraction of demand1 "3D printer (non - metal)" and demand2 "Stainless steel process" to study the name of the manufacturing resources and services.The name of the manufacturing resource is similar to the name of the requirements service as shown in table 4 .

Table 4 name similarity

\begin{tabular}{c|cc}
\hline & demand1 & demand2 \\
\hline 3D & 0.118 & 0 \\
processing & 0 & 0.233 \\
wheel & 0 & 0 \\
Cast & 0 & 0 \\
surfacing & 0 & 0.028 \\
forging & 0 & 0.028 \\
distribution & 0 & 0 \\
simulation & 0 & 0 \\
\hline
\end{tabular}

The results show that the similarity of demand1 and manufacturing resource "3D" is higher, and the similarity of demand2 and manufacturing resource "processing" is higher.

Because demand 1 demand 2 are extracted from "umade" website, the attributes of the object so this way as long as researching the semantic similarity between a manufacturing resources and demand services 1.The attribute set for demand service 1 is shown in table 5 .

Table 5 demand1 property set

\begin{tabular}{cc}
\hline & demand1 \\
\hline Type & design \\
Location & Jiangxia District, Wuhan City, Hubei Province \\
State & Over \\
Pretime & 30 (day) \\
Price & 150000 (dollar) \\
Duration & 2 (day) \\
\hline
\end{tabular}

According to the property set of demand1 and the property set of the manufacturing resource, the similarity of the attribute semantics of the manufacturing resource and the demand service is shown as follows:

$$
\begin{aligned}
& )=\frac{|\cap|}{|\cap|+\partial(,) /+(1-\partial(,)) \mid}= \\
& \frac{3}{3+0.5 * 3+0.5 * 2}=0.545
\end{aligned}
$$

in this paper, the manufacturing resources compared and the requirements of the service have the same depth, that here the default is 
0.5 .

In order to get integrated semantic similarity of demand1 - demand2 and manufacturing resources, combineing the results of each calculation, because of attributes of manufacturing resources and demand service are exactly same, this article uses the weight allocation plan proposed by the literature [8], name the weights of similarity is 0.7 , attribute weights of semantic similarity of 0.3.According to the allocation of weights, the comprehensive semantic similarity of demand 1 and demand 2 and the manufacturing resource service are obtained, as shown in table 6 .

Table 6 comprehensive similarity

\begin{tabular}{c|cc}
\hline & demand1 & demand2 \\
\hline 3D & 0.246 & 0.164 \\
processing & 0.164 & 0.327 \\
wheel & 0.164 & 0.164 \\
Cast & 0.164 & 0.164 \\
surfacing & 0.164 & 0.183 \\
forging & 0.164 & 0.183 \\
distribution & 0.164 & 0.164 \\
simulation & 0.164 & 0.164 \\
\hline
\end{tabular}

As can be seen from the table,demand 1 has the highest similarity with manufacturing resource "3D", and the similarity of demand 2 and "processing" is the highest.

\section{Conclusion}

Through the study of this article, we found using the concept of similarity of manufacturing resources and the demand for cloud environment similarity calculation service, It provides a basis for matching the subsequent manufacturing resources to the requirements services.The lack of research is in the use of the WordNet corpus, and the number of nouns associated with manufacturing resources is small, which may affect the calculation results.

\section{References}

[1] Y.J.HU, L.Z.Wu,Reviw on theory and method of cloud manufacturingservice evaluation.Computer Integrated Manufacturing Systems, Vol.03 (2017):640-649.

[2] S.P.YI, Overview of cloud manufacturing service based on lifecycle theory,Computer Integrated Manufacturing Systems., Vol. 04 (2016):871883.

[3]C. ZHAO, Simulation platform for transaction processes in cloud manufacturing,Computer Integrated Manufacturing Systems, Vol. 01 (2016):25-32.

[4] Z.F.LIAO,A Chinese Short Text Similarity Algorithm Based on Semantic and Syntax,Journal of hunan university (natural science edition), Vol. 02 (2016):135-140.

[5] R. Roy, Development and application of a metric on semantic nets. IEEE transactions on systems, man, and cybernetics, Vol. 19(1) (1989):17-30.

[6] A.Tversky, Features of similarity, Psychological review, Vol.84(4) (1977):327.

[7] L.W.Jian,Simliarity calculating model based on manufacturing resource ontology,Computer Integrated Manufacturing Systems, Vol. 11 (2010):2468-2474.

[8] B.DING,Research on cocept semantic similarity of manufacturing resource ontology,Application Research of Computers, Vol. 01 (2016):2831. 